\title{
Does Exposure to Psychosocial Adversity Enhance Deception Detection Ability?
}

\author{
Willem E. Frankenhuis, Marieke F. A. Roelofs, and Sarah A. de Vries \\ Radboud University Nijmegen
}

\begin{abstract}
People who grow up under stressful conditions tend to score lower on conventional assessments of cognitive abilities. They might, however, develop enhanced mental skills and abilities for solving problems that are more ecologically relevant to them. We present 2 studies examining whether psychosocial adversity (i.e., exposure to neighborhood violence and to harsh parenting) enhances the ability to detect deception. Our results, based on Signal Detection and Bayesian analyses, are mixed. In Study 1, we find no support for our hypothesis that exposure to psychosocial adversity enhances deception detection ability. In Study 2, we do find that only harsher parenting predicts greater accuracy. This evidence is either weak or strong, depending on whether we compare our hypothesis to the null hypothesis or an impairment model, respectively. In both studies, we find no relationship between neighborhood violence and accuracy. Although the implications of our findings are modest, we hope they will encourage future research focused on the skills and abilities of people who develop in harsh environments.
\end{abstract}

Keywords: neighborhood violence, harsh parenting, deception detection, Bayesian statistics, signal detection theory

Supplemental materials: http://dx.doi.org/10.1037/ebs0000103.supp

Growing up in a harsh environment (e.g., a dangerous neighborhood) has profound and possibly lasting impacts on cognition. People who develop in such environments tend to score lower on assessments of cognitive abilities (e.g., IQ, inhibition), which predict significant life outcomes (e.g., health, wealth, longevity; Ellis,

This article was published Online First August 28, 2017. Willem E. Frankenhuis, Marieke F. A. Roelofs, and Sarah A. de Vries, Behavioural Science Institute, Radboud University Nijmegen.

We thank all participants, staff, and community organizations that facilitated this research. We thank Tita Gonzalez, Chris Street, Jolene Tan, Leanne ten Brinke, Leonid Tiokhin, Andreas Wilke, and Ethan Young, for feedback on the manuscript. We thank Eric-Jan Wagenmakers for feedback on Bayesian analyses, and Jeroen Borghuis for co-developing the questionnaires.

This research was supported by grants from the Netherlands Organization for Scientific Research (016.155.195) and the Robert Wood Johnson Foundation (73657).

Correspondence concerning this article should be addressed to Willem E. Frankenhuis, Behavioural Science Institute, Radboud University Nijmegen, Montessorilaan 3, P.O. Box 9104, 6500 HE, Nijmegen, the Netherlands. E-mail: wfrankenhuis@gmail.com
Bianchi, Griskevicius, \& Frankenhuis, 2017; Frankenhuis \& de Weerth, 2013). The prevailing view among scientists, clinicians, and policymakers is, therefore, that harsh environments impair cognition.

Frankenhuis and de Weerth (2013) have challenged this consensus by proposing the specialization hypothesis: Harsh environments do not exclusively impair cognition; rather, people's minds also become developmentally tailored, or "specialized," for problem solving relevant in such environments (see also Ellis et al., 2017). These problems may require different mental skills from those assessed on conventional tests of cognitive abilities (e.g., the Raven's Progressive Matrices). For instance, in unpredictable environments, frequent attention shifting may be adaptive because it enhances detection of imminent threats and fleeting opportunities, even if it reduces performance on tests of sustained attention (Mittal, Griskevicius, Simpson, Sung, \& Young, 2015).

Determining whether cognition in harsh environments is impaired, specialized, or both is 
of applied and scientific importance (Ellis et al., 2017; Frankenhuis \& de Weerth, 2013). If a harsh environment results in the development of certain unique competences (e.g., enhanced deception detection ability), in addition to impairments, these skills might be leveraged to the benefit of individuals, their families, and society at large, in education, interventions, and employment (e.g., as law-enforcement officers who interrogate crime suspects).

\section{Enhanced Cognition in Harsh Environments}

The specialization hypothesis predicts that harsh-adapted people show enhanced cognition on tasks that match recurrent problems in their environments (Ellis et al., 2017; Frankenhuis \& de Weerth, 2013), consistent with some extant research. For instance, physically abused children may be more accurate and faster at identifying angry facial expressions from degraded pictures than their nonabused peers (Pollak, 2008) and be better at memorizing threats (Goodman, Quas, \& Ogle, 2010). In adults, socioeconomic adversity and attachment insecurity predicts enhanced empathic accuracy and mind-reading abilities (Shoda \& McConnell, 2013). Adults from lower socioeconomic status (SES) may also display greater empathic accuracy than their higher SES counterparts (Kraus, Côté, \& Keltner, 2010), and adults who are more anxiously attached appear to be better at detecting deceit (Ein-Dor \& Perry, 2014).

We hypothesize that people who grow up in harsh environments develop enhanced abilities for detecting lies, defined as "intentional attempts to convince others of information that the communicator believes to be untrue (i.e., lies of commission)" (ten Brinke, Vohs, \& Carney, 2016, p. 579; Vrij, 2008), across contexts. Theoretically, in harsh environments people struggle to meet their basic needs in different domains of life (e.g., food, safety, shelter). This increases scope for conflict and creates incentives to deceive others to obtain and maintain access to scarce resources. Interviews with people who perform exceptionally well on deception detection tasks (so-called wizards), suggest these individuals might have had "unusual childhoods":

\begin{abstract}
Another consistency among the handful of experts who have been interviewed so far is that most of them have had unusual childhoods. Some of them did not speak English until grade school, some are children of alcoholics, some had working mothers, when not many children their age did. Most of them report being aware of changes in the emotional levels of those around them from a very early age. (O'Sullivan \& Ekman, 2004, p. 281)
\end{abstract}

Whereas the average score on deception detection tasks is at $54 \%$ (near chance) in the general population (C. F. Bond \& DePaulo, 2006; ten Brinke et al., 2016), these "wizards" scored over $80 \%$ on multiple tasks. There is, however, statistical debate about whether the performance of wizards deviates from what one expects under a coin-flipping model (i.e., people score $50 \%$ on average) and a research-based model (i.e., people score $54 \%$ on average), considering the sample sizes of studies (G. D. Bond, 2008; C. F. Bond \& Uysal, 2007). For our purpose, it is not crucial that wizards exist, just that people vary in their deception detection abilities (though the extent of such individual differences remains under debate; Aamodt \& Custer, 2006; C. F. Bond \& DePaulo, 2008).

\section{The Current Research}

In the evolutionary developmental literature, "harshness" refers to extrinsic morbidity and mortality, that is, unpreventable causes of disability and death (Ellis, Del Giudice, et al., 2012). In this article, we focus on two psychosocial adversity factors that contribute to environmental harshness: exposure to neighborhood violence and harsh parenting. In dangerous neighborhoods, distinguishing lying from truth telling may be crucial, because the consequences for fitness of trusting or distrusting claims made by others are large (e.g., "Is this street really safe?" and "Will Mike protect me like he says?"). Furthermore, harsher parents pose threats to their children, imposing larger costs on them, so children with harsh parents can gain much from being able to judge whether their parents are telling the truth or lying (e.g., "Will my parents beat or humiliate me, if I confess to having skipped school, even when they say they won't?").

We analyze the relationships between past and current exposure to neighborhood violence and deception detection ability separately, in an exploratory manner, because we think their con- 
tributions might differ in weight, but we do not have strong expectations about which is the better predictor. If deception detection ability develops gradually and becomes trait-like, we expect past (e.g., childhood) exposures to be a better predictor (Frankenhuis, Panchanathan, \& Nettle, 2016). In contrast, if it adjusts dynamically in response to ongoing contextual factors throughout adulthood (e.g., currently living in a dangerous neighborhood), we expect more recent exposures to be a better predictor.

\section{Predictions}

We present two studies. The first study compares the deception detection abilities of college students, who tend to be from low-risk (middleor high-SES) backgrounds, with those of a socioeconomically diverse community sample, which includes more individuals who have been exposed to and currently experience significant social and material hardships. We expected the community sample to be more accurate at detecting deception, whereas a general impairment view predicts the opposite pattern. At an individual level, we expected people exposed to more violence, and to harsher parenting, to be more accurate at detect deception, whereas a general impairment view predicts the opposite pattern. The second study examines these same hypotheses in a different sample of college students and on a different task.

We conducted our two studies in parallel. In Study 1 (led by Willem E. Frankenhuis), we viewed neighborhood violence as a confirmatory variable, and harsh parenting as an exploratory variable (see preregistration). We did not preregister Study 2, but had the same predictions as in Study 1. In Study 2 (led by Sarah A. de Vries), which we conducted in parallel, we viewed both independent variables (neighborhood violence and harsh parenting) as confirmatory. In both studies, we viewed bias (explained below) as an exploratory dependent variable.

In both studies, we use a conventional cognitive test-the Raven's Progressive Matrices (hereinafter, Raven) — in order to assess analytic intelligence. Based on both theoretical accounts as well as extant research showing negative associations between exposure to adversity and analytic intelligence (see Ellis et al., 2017; Frankenhuis \& de Weerth, 2013), we expect nega- tive associations between neighborhood violence and harsh parenting and performance on the Raven.

In both studies, we explored whether participants were able to estimate their own deception detection ability, but found no evidence for associations between self-ratings and actual performance. We also asked participants what cues they used to form their judgments. Consistent with previous research (DePaulo et al., 2003), participants answered relying on verbal cues (such as stuttering, intonation, unconvincing arguments) as well as nonverbal cues (such as blushing, avoiding eye contact, body posture, fidgeting).

For exploratory purposes, we measured past and current involvement in violence, past and current poverty, and life expectancy. Although some of these variables showed significant correlations with our dependent variables, none of them consistently did so in both studies; hence we do not discuss them.

\section{Study 1}

\section{Participants}

Our goal was to test 90 participants: 45 from the community sample and 45 students. We actually tested 102 participants: 49 in the community sample and 53 students. We excluded three participants from the community sample who did not complete the questionnaires or the deception detection task, and nine (eight of whom were students) whom we accidentally tested beyond our preregistered sample size due to parallel testing at different locations (we excluded the last participants we tested, based on their date and time of participation, without having seen their data). The final sample comprised 90 participants: 45 in the community sample $\left(M_{\text {age }}=42, S D=12\right.$, range: $18-65 ; 33$ females) and 45 students $\left(M_{\text {age }}=23, S D=6\right.$, range: $19-61 ; 30$ females). All participants received $€ 10$ or $€ 15$ compensation, depending on whether they completed the test battery in 60 or $90 \mathrm{~min}$ (see the Procedure section).

Following our preregistration, we do not report analyses of age below. Given the age difference between the student and community samples, however, we checked for main effects of age, and for interactions effects between age and our independent variables, finding neither. 


\section{Procedure}

We recruited the community sample via two different agencies that aim to improve the lives of people living in disadvantaged conditions for Dutch standards, including homelessness, eviction, unemployment, and exposure to family violence. We recruited this sample using folders and posters, and with the help of employees of these agencies who informed people about the possibility of participating. We recruited the students via an online sign-up system of Radboud University.

Depending on the place of recruitment, participants completed the test battery individually in a test cubicle at the university or in a room of one of the community agencies. All participants completed the same test battery, which comprised the present studies and three other ones measuring mental skills unrelated to deception detection. All instructions and questions were presented in Dutch. Students completed the test battery on a 24-inch desktop computer and the community sample on a 17-inch laptop computer.

After we provided verbal instructions, participants completed the questionnaire (see below) and three other studies before they started with the deception detection study. Participants viewed the videos showing deception detection trials (see below) sequentially and in the same order. After each video, participants indicated whether a suspect was lying or telling the truth. Following the test phase, participants viewed two additional videos, which we used to measure English proficiency. All videos were presented in the center of the screen in an area of $\sim 700 \times 750$ pixels. Finally, participants completed the abbreviated version of the Raven (Bilker et al., 2012). Items were presented in an area that filled $\sim 90 \% \times 70 \%$ of the screen. Participants received their compensation after completing the test battery.

\section{Materials}

We preregistered our hypotheses, sample size, statistical analyses, and materials for Study 1 , and provide the data for Studies 1 and 2 at the Open Science Framework on the following website: https://osf.io/c8fne/. Both studies have been approved by the ethics committee of the Faculty of Social Sciences of Radboud Univer- sity Nijmegen (CSW2014-1310-250; Verborgen Talenten [English translation: Hidden Talents]).

Stimuli. We examined deception detection accuracy using a shortened version of the highstakes mock-paradigm videos (in English) developed by ten Brinke, Stimson, and Carney (2014). We did not use the complete videos for three reasons. First, according to some previous research, "Giving people less information- $5 \mathrm{~s}$ of video footage versus $3 \mathrm{~min}$-improves the accuracy of explicit reports of lie detection by up to $15 \%$ " (ten Brinke et al., 2016, p. 584; see also Albrechtsen, Meissner, \& Susa, 2009; but see Street \& Vadillo, 2016). Second, in working with our community sample, there were considerable time constraints (e.g., some people bring their children, who cannot wait for long). Third, the current study was part of a test battery that included multiple studies, further limiting the available time.

In the videos, $\$ 100$ were hidden in a test cubicle. Six of 12 individuals featuring in these videos were randomly assigned to take the money and the other 6 to not take it. All participants could earn the money only if they convinced the experimenter that they did not steal it (i.e., half of the participants lied). Convincing suspects could earn an additional \$500 through a lottery. The experimenter asked questions unrelated to the possible theft (e.g., "What are you wearing today?") as well as ones related to it (e.g., "Did you steal the money?"). We used only those four questions related to the possible theft. Video segments lasted $46 \mathrm{~s}$ on average $(S D=28$; with truth segments, $M=42, S D=$ 6; lie segments, $M=52, S D=18$ ).

We used English videos even though our participants were Dutch, as we considered replicating the study in a U.S. sample, if results suggested enhanced deception detection accuracy in our community sample. Our participants watched three snippets of two of ten Brinke et al.'s (2014) videos, showing suspects from the shoulders up, while answering questions unrelated to the possible theft. To assess English proficiency, we asked six multiple-choice questions (e.g., "Which color are the suspect's pants?"), each with five options (e.g., "Yellow," "Brown," "Black," "White," "Blue").

Neighborhood violence. We measured past (seven items; e.g., "I grew up in a safe neighborhood"; $\alpha=.86$ ) and current (seven 
items; e.g., "Physical fights are common in my neighborhood"; $\alpha=.88$ ) exposure to neighborhood violence using the Neighborhood Violence Scale (NVS; see the online supplemental materials for subscales and their development). These subscales are exactly the same except in referring to the past ( $<18$ years) or present (current experiences). Participants rated items on a scale from 1 (completely agree) to 7 (disagree).

Harsh parenting. We assessed parental behavior using an abbreviated version of the Parenting Questionnaire $(\alpha=.90)$ developed by Ellis, Schlomer, Tilley, and Butler (2012). The questionnaire was translated into Dutch. This questionnaire consisted of four subscales: maternal warmth $(\alpha=.89)$, paternal warmth $(\alpha=.80)$, maternal aggression $(\alpha=.84)$, and paternal aggression $(\alpha=.89)$. The maternal and paternal warmth subscales each consisted of six items, and the maternal and paternal aggression scales each consisted of four items. The items were statements (e.g., "My mother pushed, grabbed, or slapped me"). Participants rated the extent to which these statements applied to their childhood (until age 16) on a scale from 1 (never) to 5 (always). We computed the mean over all four subscales to obtain a single harsh parenting score per participant. A higher score indicates lower paternal and maternal warmth, and higher paternal and maternal aggression. If participants had one parent, we computed the mean over the two subscales pertaining to that parent.

Raven. We used an abbreviated nine-item version of the Raven (Bilker et al., 2012) to measure analytic intelligence. Participants complete an incomplete geometric pattern by selecting the missing element from a set of (six or eight) options. Items progressively increased in difficulty.

\section{Results}

Before conducting our main analyses, Shapiro-Wilk tests indicated that our data were unlikely to be drawn from a normally distributed population; hence we report nonparametric analyses. We report medians for groups, and Kendall's tau for correlations, which has more attractive qualities than Spearman's rho (Gibbons, 1993).
Signal detection theory. We analyze accuracy and bias using signal detection theory (Green \& Swets, 1966/1974; Macmillan \& Creelman, 2005). Participants may rate truths as truths (correct rejections), truths as lies (false alarms), lies as truths (misses), and lies as lies (hits). We used the proportion of hits and false alarm to compute accuracy $\left(d^{\prime}\right)$ and bias $(c$; for formulas, see Stanislaw \& Todorov, 1999). Distinguishing accuracy and bias is crucial when the number of signal (e.g., lie) and noise (e.g., truth) trials is not equal. For instance, if $80 \%$ of all trials depict lies, mistrustful participants who estimate all trials to be lies attain $80 \%$ correct, even when they do not discriminate truths from lies.

The discriminability $d^{\prime}$ captures the extent to which an individual is able to discriminate between signal (lie) and no-signal (truth) trials. A $d^{\prime}$ of zero indicates no discriminability, and higher $d^{\prime}$ greater accuracy. Criterion $c$ indicates the evidentiary bar for rating a trial as a signal trial: zero $c$ indicates no bias, negative $c$ a low evidentiary bar (lie bias), and positive $c$ a high evidentiary bar (truth bias; for more explanation, see Tan, Luan, \& Katsikopoulos, 2017).

Some of our participants had $0 \%$ or $100 \%$ hits, false alarms, or both, which precludes calculation of $d^{\prime}$ and $c$. Hence we applied the log-linear method (Snodgrass \& Corwin, 1988), which improves estimates when there are extreme values (e.g., Brown \& White, 2005; Hautus \& Lee, 2006; Stanislaw \& Todorov, 1999), to all participants: adding 0.5 to the frequencies of hits and false alarms, and adding 1 to the number of signal and noise trials, before computing proportions used to calculate $z$ scores (used to compute $d^{\prime}$ and $c$ ).

We computed signal detection analyses using $\mathrm{R}$ (version 3.3.0; R Core Team, 2016). We also analyzed our data using generalized linear mixed models (GLMMs; Watkins \& Martire, 2015). As these analyses offer similar conclusions as our signal detection analyses for both studies, we report GLMMs in the supplemental materials.

Bayes factors. We also estimate Bayes Factors (BFs; Jeffreys, 1961; Rouder, Speckman, Sun, Morey, \& Iverson, 2009). BFs quantify the relative evidence for two models (statistical descriptions of hypotheses), typically a null hypothesis $\left(H_{0}\right)$ and an alternative hypothesis $\left(H_{1}\right)$. Whereas frequentist null-hypothesis 
testing forces an all-or-none decision about rejecting $H_{0}$, BFs allow quantification of support for $H_{0}$ (Wagenmakers, 2007). $\mathrm{BF}_{10}$ denotes a ratio: the likelihood of the data conditional on Model 1, $\mathrm{P}\left(\mathrm{D} \mid \mathrm{M}_{1}\right)$, divided by the likelihood of the data conditional on Model $0, \mathrm{P}\left(\mathrm{D} \mid \mathrm{M}_{0}\right)$. For example, if $\mathrm{BF}_{10}=4$, the observed data are four times more likely to have occurred on Model 1 than on Model 0 (Lee \& Wagenmakers, 2014).

Bayesian $t$ tests assume that data are sampled from a normally distributed population. As our data tend to violate this assumption, our $\mathrm{BF}$ estimates will be suboptimal. However, even if quantitatively imperfect, these estimates are qualitatively informative. We conduct our Bayesian analyses using JASP software (JASP Team, 2016). We use JASP's default priors: for Bayesian Kendall's tau correlations, a uniform distribution (a stretched beta distribution with width 1) for Spearman's rho, mapped onto Kendall's tau; for Bayesian $t$ tests, a Cauchy distribution with width 0.707 .

Following convention, we report all $p$ values as two-tailed. We report Bayes factors (BFs) as two-sided if the adaptation and general impairment views make opposing predictions (subscripts 0 and 1), and one-sided if both views make the same prediction (subscripts 0 and plus or minus). When the adaptation and general impairment views make opposing predictions (i.e., two-sided BFs), we compare $\mathrm{M}_{1}(\theta \neq 0)$ with $\mathrm{M}_{0}(\theta=0)$-rather than the adaptation model $(\theta>0)$ with the impairment model $(\theta<$ $0)$ - so BFs and $p$ values are based on comparisons of the same hypotheses. This approach is conservative: It understates the evidence for whichever hypothesis is supported (adaptation or impairment hypothesis). For confirmative analyses with a $p$ value below .05 , we also report BFs comparing the adaptation model $(\theta>0)$ with the impairment model $(\theta<0)$. We calculate this $\mathrm{BF}_{+-}$by multiplying two $\mathrm{BFs}$ obtained by one-sided tests:

$$
\mathrm{BF}_{+-}=\mathrm{BF}_{+0} \times \mathrm{BF}_{0-},
$$

in which we obtain $\mathrm{BF}_{+0}$ by comparing the adaptation model with $\mathrm{M}_{0}$, and $\mathrm{BF}_{0-}$ by comparing $\mathrm{M}_{0}$ with the impairment model. As BFs are transitive, multiplying these two produces $\mathrm{BF}_{+-}$.

Table 1 shows the descriptive and inferential statistics evidencing differences in past and current exposures to violence, and to harsh parenting, between the student and the community sample. The correlation coefficients between our independent variables ranged from .26 to .46 .

Before conducting our main analyses, we determined that the English proficiency of our participants was sufficient to understand the videos: 74 participants answered at least four of the five-option multiple-choice questions correctly, and 16 fewer than four. Moreover, there was a negative correlation between English proficiency and $d^{\prime}\left(r_{\tau}=-.18, p=.04\right.$; however, $\left.\mathrm{BF}_{10}=2.7\right)$. Greater English proficiency predicted lower accuracy.

Accuracy $\boldsymbol{d}^{\prime}$. A one-sample Wilcoxon signed-ranks test did not indicate that participants' $d$ 's $(M d n=0$; range: $-2.26-1.58)$ differed from zero $\left(V=1001.5, p=.16 ; \mathrm{BF}_{0+}=\right.$ 2.2). Comparing groups, a Mann-Whitney test did not indicate a difference in $d^{\prime}$ between the

Table 1

Descriptive Statistics for Each Group on the Independent Variables

\begin{tabular}{|c|c|c|c|c|c|}
\hline \multirow[b]{3}{*}{ Scale } & \multicolumn{4}{|c|}{ Study 1} & \multirow[t]{2}{*}{ Study 2} \\
\hline & \multirow{2}{*}{$\begin{array}{l}\text { Community, } \\
\text { median (range) }\end{array}$} & \multirow{2}{*}{$\begin{array}{c}\text { Students, } \\
\text { median (range) }\end{array}$} & \multicolumn{2}{|c|}{ Test } & \\
\hline & & & W & $\mathrm{BF}_{+0}$ & $\begin{array}{c}\text { Students, } \\
\text { median (range) }\end{array}$ \\
\hline Past NVS & $3.29(1.14-6.43)$ & $1.71(1.14-6.00)$ & $1,548^{* *}$ & 977 & $1.71(1.00-5.29)$ \\
\hline Current NVS & $3.86(1.14-6.14)$ & $2.43(1.29-5.71)$ & $1,635^{* *}$ & 268,866 & $2.29(1.14-5.29)$ \\
\hline Harsh parenting & $1.90(1.00-4.88)$ & $1.42(1.00-2.92)$ & $1,292^{*}$ & 10 & $1.41(1.00-4.08)$ \\
\hline
\end{tabular}

Note. For Study 1, inferential statistics comparing groups using Wilcoxon signed-rank tests ( $p$ values) and Bayes factors (computed using Bayesian independent-samples $T$ tests). $\mathrm{W}=$ Wilcoxon signed-rank test; $\mathrm{BF}=$ Bayes factors; $\mathrm{NVS}=$ Neighborhood Violence Scale.

${ }^{*} p<.01 .{ }^{* *} p<.001$. 
community sample $(M d n=0$; range: $-1.83-1.47)$ and students $(M d n=0$; range: -2.26-1.58), $U=1176.5, p=.18 ; \mathrm{BF}_{01}=$ 2.0. There were no correlations between past $\left(r_{\tau}=.06, p=.60 ; \mathrm{BF}_{01}=5.4\right)$ and current $\left(r_{\tau}=.03, p=.76 ; \mathrm{BF}_{01}=6.5\right)$ exposure to violence and $d^{\prime}$, nor between harsh parenting and $d^{\prime}\left(r_{\tau}=-.07, p=.50 ; \mathrm{BF}_{01}=4.4\right)$.

Bias $c$. A one-sample Wilcoxon signedranks test indicated that participants' $c \mathrm{~s}(M d n=$ .18) differed significantly from zero $(V=2190$, $\left.p<.001 ; \mathrm{BF}_{+0}>1,000,000\right)$. Comparing groups, a Mann-Whitney test did not indicate a difference of $c$ between the community sample $(M d n=.18)$ and students $(M d n=.21 ; U=$ 909.5, $\left.p=.40 ; \mathrm{BF}_{0-}=2.1\right)$. There were no correlations between past $\left(r_{\tau}=-.08, p=.45\right.$; $\left.\mathrm{BF}_{0-}=2.2\right)$ and current $\left(r_{\tau}=-.09, p=.42\right.$; $\left.\mathrm{BF}_{0-}=2.0\right)$ exposure to violence and $c$, nor between harsh parenting and $c\left(r_{\tau}=-.10, p=\right.$ $.35 ; \mathrm{BF}_{0-}=1.5$ ).

Raven. We converted the scores of the abbreviated version of the Raven into standard test scores using a validated function (Bilker et al., 2012). We excluded one participant who did not complete this test. Comparing groups, a MannWhitney test indicated that students $(M d n=$ 51.68) scored higher on the Raven than the community sample $(M d n=39.64 ; U=458$, $\left.p<.01 ; \mathrm{BF}_{+0}=1,771\right)$. At an individual level, there were no correlations between past $\left(r_{\tau}=\right.$ $\left.-.13, p=.21 ; \mathrm{BF}_{-0}=1.5\right)$ and current $\left(r_{\tau}=\right.$ $-.19, p=.08$; however, $\left.\mathrm{BF}_{-0}=8.2\right)$ exposure to violence and Raven scores. There was no correlation between harsh parenting and Raven scores $\left(r_{\tau}=-.01, p=.94 ; \mathrm{BF}_{0-}=6.5\right)$, nor between $d^{\prime}$ and Raven scores $\left(r_{\tau}=-.002, p=\right.$ $.98 ; \mathrm{BF}_{01}=7.2$ ).

\section{Study 2}

The second study examines our hypotheses in a different sample of college students and on a different task. Here, we used a task featuring Dutch-speaking and culturally Dutch students to assess deception detection. This ensures that any failure to detect deception was not due to an inability to understand the person being judged, but instead reflects participants' skill levels. As in Study 1, there were real stakes for the people in the videos, but not for our participants.

\section{Participants}

Our goal was to test 85 participants. We ended up testing 88 participants, because we had to exclude the first three due to malfunctioning questionnaires. The final sample comprised 85 participants $\left(M_{\text {age }}=21.42, S D=\right.$ 2.67, range: $18-30 ; 66$ females, one person identified as "other"). All participants were college students and received $€ 5$ compensation.

\section{Procedure}

We recruited participants via an online sign-up system of Radboud University. Criteria for signing up were the ability to understand Dutch and being between 18 and 35 years old.

Participants completed the test battery individually in a test cubicle at the university. All participants completed the same test battery, which comprised the present studies and one other test measuring mental skills unrelated to deception detection. All instructions and questions were presented in Dutch. Participants completed the test battery on a 17 -inch laptop computer.

After we provided verbal instructions, participants completed the questionnaire before they started with the deception detection study. Participants viewed the videos (see below) sequentially and in the same order. After each video, participants judged whether people in the videos were telling the truth or lying. All videos were presented in the center of the screen in an area of $\sim 700 \times 750$ pixels. Next, participants completed an unrelated study and the abbreviated version of the Raven (Bilker et al., 2012). Items were presented in an area that filled $\sim 90 \% \times 70 \%$ of the screen. Participants received compensation after completing the test battery.

\section{Materials}

Stimuli. We developed a video task to examine deception detection accuracy. We recruited 10 pairs of students (16 women and 4 men) in a cafeteria of Radboud University and asked them to play a game called "Split or Steal" (Van den Assem, Van Dolder, \& Thaler, 2012). These participants did not participate in the main study and had provided permission to be filmed, and for the resulting footage to be shown to fellow students. Both players in a pair 
had to choose between cooperating (split) and defecting (steal) by picking one of two cards: one indicating split and the other steal. Both players had $1 \mathrm{~min}$ to deliberate about their choice, after which they would lay down the card with the option of their choice, text facing down. If both players chose split, both received $€ 7.50$. If one chose split and the other steal, the player who chose steal would receive $€ 10$ and the other only $€ 5$. If both were to choose steal each would receive $€ 5$. The structure of the Split or Steal game is almost identical to that of the Prisoner's Dilemma. To ensure that a sufficient number of players chose both options, one of the players in each pair was given an instruction to either split or steal. They were told not to tell the other player they had been given an instruction, and to pretend they intended to split. Of the players with an instruction, $50 \%$ was given an instruction to steal, and the other $50 \%$ to split. Only one (10\%) of the players without an instruction chose to steal.

During the game, one camera filmed each player, ensuring that facial expressions would be visible from the same angle as when one would be talking to the player directly (as opposed to a side view). We combined video fragments into a single video containing about the same amount of material from both players. The difference was never larger than $1.7 \mathrm{~s}$, or $3.3 \%$ of the duration of the video $(M=1.01)$. Switching from one camera to the other happened between sentences or during a pause, to ensure switches would not disturb the viewer. Videos started when players began deliberating, and ended after participants had selected their cards, but before these cards were turned over. Videos lasted $46 \mathrm{~s}$ on average $(S D=13$; with truth segments, $M=22, S D=6$; lie segments, $M=25, S D=8$ ), and were in Dutch.

Participants assessed whether the people in the videos would choose split or steal. As every player told their opponent they were going to split, participants who chose steal were lying and participants who chose split were telling the truth. For each video, participants made two judgments: one for each player (first for the person on the left, and then for the person on the right). Thus, each participant made 20 judgments in total, of which six $(30 \%)$ were about lies. In order to ensure participants would not skip parts of the video, they needed to watch a video in its entirety before selecting an answer.
Neighborhood violence. As in Study 1, we measured past $(\alpha=.84)$ and current $(\alpha=.87)$ exposure to neighborhood violence using the NVS (see the supplemental materials).

Harsh parenting. As in Study 1, we assessed parental behavior using an abbreviated version of the Parenting Questionnaire $(\alpha=$ .93; see Ellis, Schlomer, et al., 2012), which includes four subscales: maternal warmth $(\alpha=$ $.88)$, paternal warmth $(\alpha=.90)$, maternal aggression $(\alpha=.85)$, and paternal aggression $(\alpha=.86)$.

Raven. We used the same abbreviated version of the Raven as in Study 1 (Bilker et al., 2012).

\section{Results}

We report the same analyses as for Study 1. Table 1 shows descriptive statistics. The correlation coefficients between our independent variables ranged from .11 to .27 .

Accuracy $\boldsymbol{d}^{\prime}$. A one-sample Wilcoxon signed-ranks test indicated that participants' $d$ 's $(M d n=0.34$; range: $-1.12-1.32)$ differed significantly from zero $(V=2613, p<.001$; $\left.\mathrm{BF}_{+0}=530\right)$. There were no correlations between past $\left(r_{\tau}=.08, p=.29 ; \mathrm{BF}_{01}=3.8\right)$ and current $\left(r_{\tau}=-.02, p=.76 ; \mathrm{BF}_{01}=6.7\right)$ exposure to violence and $d^{\prime}$. However, there was a significant correlation between harsh parenting and $d^{\prime}\left(r_{\tau}=.17, p=.03\right.$; however, $\left.\mathrm{BF}_{10}=1.7\right)$. Harsher parenting predicted greater accuracy. Testing direction revealed strong evidence for the adaptation model compared to the impairment model $\left(\mathrm{BF}_{+-}=75\right)$.

Bias $c$. A one-sample Wilcoxon signedranks test indicated that participants' $c \mathrm{~s}(M d n=$ $0.08)$ differed significantly from zero $(V=$ $\left.2,390, p=.003 ; \mathrm{BF}_{+0}=40\right)$. There were no correlations between past $\left(r_{\tau}=-.10, p=.21\right.$; $\left.\mathrm{BF}_{0-}=1.7\right)$ and current $\left(r_{\tau}=-.10, p=.18\right.$; $\left.\mathrm{BF}_{0-}=1.5\right)$ exposure to violence and $c$. However, there was a significant correlation between harsh parenting and $c\left(r_{\tau}=-.16, p=.04\right.$; however, $\left.\mathrm{BF}_{-0}=2.7\right)$. Harsher parenting predicted a lower evidentiary bar in judging trials as lies.

Raven. There were no correlations between past $\left(r_{\tau}=-.02, p=.76 ; \mathrm{BF}_{0-}=5.4\right)$ and current $\left(r_{\tau}=-.13, p=.09 ; \mathrm{BF}_{-0}=1.2\right)$ exposure to violence and Raven scores, nor between harsh parenting and Raven scores $\left(r_{\tau}=\right.$ 
$\left..04, p=.58 ; \mathrm{BF}_{0-}=10.6\right)$. There was no correlation between $d^{\prime}$ and Raven scores $\left(r_{\tau}=\right.$ $.02, p=.83 ; \mathrm{BF}_{01}=6.9$ ).

\section{General Discussion}

Our results are mixed. In Study 1, we find no support for the hypothesis that exposure to psychosocial adversity enhances deception detection ability. In Study 2, we do find some support: Harsher parenting predicted greater accuracy. This evidence is either weak or strong, depending on whether we compare our hypothesis to the null hypothesis or an impairment model, respectively. In both studies, we observed no relationship between past or current exposure to neighborhood violence and accuracy.

A possible explanation of our mixed results across studies is that participants were able to use information in the stimuli in Study 2, but not in Study 1. Indeed, in Study 1 participants were unable to distinguish truths from lies (i.e., their $d^{\prime}$ s did not differ from zero). Low BFs indicated that the data were insensitive, providing no support for our specialization hypothesis nor for the null hypothesis. Either the stimuli of Study 1 did not provide enough information to distinguish truths from lies, or they did, but participants were not able to use this information to improve their judgments. We used stimuli known to contain information (ten Brinke et al., 2014), but then abbreviated them. In doing so, we may have lost information. Some research suggests, however, that the accuracy of explicit reports of lie detection may increase with shorter presentations (Albrechtsen et al., 2009; ten Brinke et al., 2016). Furthermore, we showed culturally American and linguistically English videos to Dutch participants, which may decrease performance (C. F. Bond \& Atoum, 2000). However, in Study 1 lower English proficiency predicted greater accuracy. We cannot assess the cultural stimuli-participant mismatch explanation with the current data.

In Study 2, harsher parenting predicted greater deception detection accuracy. The structure of the Split or Steal game resembled that of the Prisoner's Dilemma. A recent meta-analysis shows that "humans can predict each other's Prisoner's Dilemma decisions after a brief interaction with people who have incentive to deceive" (Sparks, Burleigh, \& Barclay, 2016, p.
210). Our judges may have been able to predict the behavior of the game players, and variation in this ability may have been shaped by experience with harsher parents. We do not know why, in contrast, exposure to neighborhood violence did not predict deception detection accuracy. Our parenting scale measures personal involvement in hostile social interactions (e.g., parents hurting their children), whereas the NVS measures neighborhood-level characteristics. Future research may examine whether specifically personal involvement in hostile interactions contributes to deception detection ability and, if it does, what psychological process enables this enhanced performance.

Consistent with previous research (C. F. Bond \& DePaulo, 2006), we find decisive evidence for truth bias in both studies; that is, individuals underestimated the number of deceptions. The word bias, here, refers to deviations from the evidentiary bar that maximizes accuracy in the study setting. In actual environments, however, most people tell the truth most of the time (Halevy, Shalvi, \& Verschuere, 2014). Hence participants may adjust their cuebased estimates in the lab downward by integrating real-world base rates (Street, 2015). A Bayesian view predicts the impact of base rates on judgment will be larger when cues are weaker, that is, provide less information that discriminates between options (Stamps \& Frankenhuis, 2016; Street, 2015; for a study showing that humans rely more on base rates when cues are less diagnostic, seeStreet, Bischof, Vadillo, \& Kingstone, 2016). As cues were likely to be weak in our studies, as they tend to be generally (DePaulo et al., 2003), the truth bias we observed may well result from integration of base rates (Street, 2015).

Consistent with previous research (Ellis et al., 2017; Frankenhuis \& de Weerth, 2013), students scored higher on the Raven than did the community sample. This difference may result in part from stereotype threat (concerns about confirming stereotypes about one's social group), and from community participants being less comfortable in test settings than students (e.g., some indicated feeling uncertain because they did not do well in school). Our measures of harshness, however, did not consistently predict Raven scores at an individual level in both studies (note that Bayesian analyses did support a negative correlation between current exposure 
to violence and Raven scores in Study 1). Consistent with meta-analytic results showing no relationship between deception detection ability and educational level (Aamodt \& Custer, 2006), we found no relationship between accuracy and Raven scores.

Our studies have several limitations. First, we measured past adversity exposures retrospectively. Second, we measured perceptions of, rather than actual, past and current exposure to neighborhood violence and harsh parenting. On the flip side, subjective and objective harshness measures are known to correlate in some studies (Sherman, Minich, Langen, Skufca, \& Wilke, 2016), and moreover, some studies find that perceptions are better predictors of developmental adaptations than objective indicators (Johns, 2011). Third, despite our best efforts, as we assessed the community sample in the field and in some cases with their own children nearby, we were not always able to create optimal testing conditions for this sample, as we were for students. Fourth, we have assumed that people from harsh environments develop enhanced deception detection abilities across contexts (e.g., harsh parenting predicts detecting lies in economic game). Future research could examine our hypotheses in context-specific settings, which match the settings in which harshadapted people may have honed their deception detection abilities.

At the onset we challenged the predominant view that growing up in a harsh environment impairs cognition (Ellis et al., 2017; Frankenhuis \& de Weerth, 2013). This consensus view informs policy, intervention, and education, which in turn affect the daily lives of millions of people. If the consensus view is incomplete, people may suffer while well-intended efforts and material resources are utilized in suboptimal ways. It is thus crucial to constantly scrutinize this view and consider improvements. Our goal has been to learn about the mental skills and abilities of people who develop in harsh environments. We found some evidence for the adaptation view in Study 2, and none of our results indicate that people from harsher environments are worse at detecting deception. The implications of our findings are modest, but those of future discoveries could be substantial: Rather than narrowly focusing on what harshadapted people cannot do, it is time to determine what such individuals can do well. These lenses are complementary, not mutually exclusive. The better we understand harsh-adapted minds-including their strengths - the more effectively we can tailor education, policy, and interventions to fit their needs and potentials.

\section{References}

Aamodt, M. G., \& Custer, H. (2006). Who can best catch a liar? A meta-analysis of individual differences in detecting deception. Forensic Examiner, 15, 6-11.

Albrechtsen, J. S., Meissner, C. A., \& Susa, K. J. (2009). Can intuition improve deception detection performance? Journal of Experimental Social Psychology, 45, 1052-1055. http://dx.doi .org/10.1016/j.jesp.2009.05.017

Barr, D. J., Levy, R., Scheepers, C., \& Tily, H. J. (2013). Random effects structure for confirmatory hypothesis testing: Keep it maximal. Journal of Memory and Language, 68, 255-278. http://dx.doi .org/10.1016/j.jml.2012.11.001

Bates, D., Maechler, M., Bolker, B., \& Walker, S. (2015). Fitting linear mixed-effects models using lme4. Journal of Statistical Software, 67, 1-48. http://dx.doi.org/10.18637/jss.v067.i01

Bilker, W. B., Hansen, J. A., Brensinger, C. M., Richard, J., Gur, R. E., \& Gur, R. C. (2012). Development of abbreviated nine-item forms of the Raven's standard progressive matrices test. Assessment, 19, 354-369. http://dx.doi.org/10 $.1177 / 1073191112446655$

Bond, C. F., \& Atoum, A. O. (2000). International deception. Personality and Social Psychology Bulletin, 26, 385-395. http://dx.doi.org/10.1177/ 0146167200265010

Bond, C. F., Jr., \& DePaulo, B. M. (2006). Accuracy of deception judgments. Personality and Social Psychology Review, 10, 214-234. http:// dx.doi.org/10.1207/s15327957pspr1003_2

Bond, C. F., Jr., \& DePaulo, B. M. (2008). Individual differences in judging deception: Accuracy and bias. Psychological Bulletin, 134, 477-492. http:// dx.doi.org/10.1037/0033-2909.134.4.477

Bond, C. F., Jr., \& Uysal, A. (2007). On lie detection "wizards." Law and Human Behavior, 31, 109115. http://dx.doi.org/10.1007/s10979-006-9016-1

Bond, G. D. (2008). Deception detection expertise. Law and Human Behavior, 32, 339-351. http://dx .doi.org/10.1007/s10979-007-9110-z

Brown, G. S., \& White, K. G. (2005). The optimal correction for estimating extreme discriminability. Behavior Research Methods, 37, 436-449. http:// dx.doi.org/10.3758/BF03192712

DePaulo, B. M., Lindsay, J. J., Malone, B. E., Muhlenbruck, L., Charlton, K., \& Cooper, H. (2003). Cues to deception. Psychological Bulletin, 
129, 74-118. http://dx.doi.org/10.1037/0033-2909 129.1.74

Ein-Dor, T., \& Perry, A. (2014). Full house of fears: Evidence that people high in attachment anxiety are more accurate in detecting deceit. Journal of Personality, 82, 83-92. http://dx.doi.org/10.1111/ jopy. 12035

Ellis, B. J., Bianchi, J., Griskevicius, V., \& Frankenhuis, W. E. (2017). Beyond risk and protective factors: An adaptation-based approach to resilience. Perspectives on Psychological Science. Advance online publication. http://dx.doi .org/10.1177/1745691617693054

Ellis, B. J., Del Giudice, M., Dishion, T. J., Figueredo, A. J., Gray, P., Griskevicius, V., . . . Wilson, D. S. (2012). The evolutionary basis of risky adolescent behavior: Implications for science, policy, and practice. Developmental Psychology, 48, 598-623. http://dx.doi.org/10.1037/ a0026220

Ellis, B. J., Schlomer, G. L., Tilley, E. H., \& Butler, E. A. (2012). Impact of fathers on risky sexual behavior in daughters: A genetically and environmentally controlled sibling study. Development and Psychopathology, 24, 317-332. http://dx.doi .org/10.1017/S095457941100085X

Frankenhuis, W. E., \& de Weerth, C. (2013). Does early-life exposure to stress shape or impair cognition? Current Directions in Psychological Science, 22, 407-412. http://dx.doi.org/10.1177/ 0963721413484324

Frankenhuis, W. E., Panchanathan, K., \& Nettle, D. (2016). Cognition in harsh and unpredictable environments. Current Opinion in Psychology, 7, 76-80. http://dx.doi.org/10.1016/j.copsyc.2015.08 .011

Gibbons, J. D. (1993). Nonparametric measures of association. Thousand Oaks, CA: Sage. http://dx doi.org/10.4135/9781412985291

Goodman, G. S., Quas, J. A., \& Ogle, C. M. (2010). Child maltreatment and memory. Annual Review of Psychology, 61, 325-351. http://dx.doi.org/10 .1146/annurev.psych.093008.100403

Green, D. M., \& Swets, J. A. (1974). Signal detection theory and psychophysics [Reprint]. New York, NY: Krieger. (Original work published 1966)

Halevy, R., Shalvi, S., \& Verschuere, B. (2014). Being honest about dishonesty: Correlating selfreports and actual lying. Human Communication Research, 40, 54-72. http://dx.doi.org/10.1111/ hcre. 12019

Hautus, M. J., \& Lee, A. (2006). Estimating sensitivity and bias in a yes/no task. British Journal of Mathematical and Statistical Psychology, 59, 257273. http://dx.doi.org/10.1348/000711005X65753

JASP Team. (2016). JASP (Version 0.8) [Computer software]. Retrieved from https://jasp-stats.org/
Jeffreys, H. (1961). Theory of probability. Oxford, UK: Oxford University Press.

Johns, S. E. (2011). Perceived environmental risk as a predictor of teenage motherhood in a British population. Health \& Place, 17, 122-131. http:// dx.doi.org/10.1016/j.healthplace.2010.09.006

Kraus, M. W., Côté, S., \& Keltner, D. (2010). Social class, contextualism, and empathic accuracy. Psychological Science, 21, 1716-1723. http://dx.doi .org/10.1177/0956797610387613

Lee, M. D., \& Wagenmakers, E. J. (2014). Bayesian cognitive modeling: A practical course. New York, NY: Cambridge University Press.

Macmillan, N. A., \& Creelman, C. D. (2005). Detection theory: A user's guide. Mahwah, NJ: Erlbaum.

Mittal, C., Griskevicius, V., Simpson, J. A., Sung, S., \& Young, E. S. (2015). Cognitive adaptations to stressful environments: When childhood adversity enhances adult executive function. Journal of Personality and Social Psychology, 109, 604-621. http://dx.doi.org/10.1037/pspi0000028

O'Sullivan, M., \& Ekman, P. (2004). The wizards of deception detection. In A. Granhang \& L. A. Stromwall (Eds.), Deception detection in forensic contexts (pp. 269-286). Cambridge, UK: Cambridge Press. http://dx.doi.org/10.1017/CBO97 80511490071.012

Pollak, S. D. (2008). Mechanisms linking early experience and the emergence of emotions: Illustrations from the study of maltreated children. Current Directions in Psychological Science, 17, 370375. http://dx.doi.org/10.1111/j.1467-8721.2008 .00608.x

R Core Team. (2016). R: A language and environment for statistical computing. Vienna, Austria: R Foundation for Statistical Computing. Retrieved from https://www.Rproject.org/

Rouder, J. N., Speckman, P. L., Sun, D., Morey, R. D., \& Iverson, G. (2009). Bayesian $t$ tests for accepting and rejecting the null hypothesis. Psychonomic Bulletin \& Review, 16, 225-237. http:// dx.doi.org/10.3758/PBR.16.2.225

Sherman, A. K., Minich, S. H., Langen, T. A., Skufca, J., \& Wilke, A. (2016). Are college students' assessments of threat shaped by the dangers of their childhood environment? Journal of Interpersonal Violence, 31, 2006-2025. http://dx.doi .org/10.1177/0886260515572473

Shoda, T. M., \& McConnell, A. R. (2013). Interpersonal sensitivity and self-knowledge: Those chronic for trustworthiness are more accurate at detecting it in others. Journal of Experimental Social Psychology, 49, 440-443. http://dx.doi.org/ 10.1016/j.jesp.2012.12.011

Singmann, H., Bolker, B., Westfall, J., \& Aust, F. (2016). Afex: Analysis of factorial experiments ( $\mathrm{R}$ package version $0.16-1$ ). Retrieved from https:// CRAN.R-project.org/package $=$ afex 
Snodgrass, J. G., \& Corwin, J. (1988). Pragmatics of measuring recognition memory: Applications to dementia and amnesia. Journal of Experimental Psychology: General, 117, 34-50. http://dx.doi .org/10.1037/0096-3445.117.1.34

Sparks, A., Burleigh, T., \& Barclay, P. (2016). We can see inside: Accurate prediction of prisoner's dilemma decisions in announced games following a face-to-face interaction. Evolution and Human Behavior, 37, 210-216. http://dx.doi.org/10.1016/ j.evolhumbehav.2015.11.003

Stamps, J. A., \& Frankenhuis, W. E. (2016). Bayesian models of development. Trends in Ecology \& Evolution, 31, 260-268. http://dx.doi.org/10.1016/ j.tree.2016.01.012

Stanislaw, H., \& Todorov, N. (1999). Calculation of signal detection theory measures. Behavior Research Methods, Instruments \& Computers, 31, 137-149. http://dx.doi.org/10.3758/BF03207704

Street, C. N. H. (2015). ALIED: Humans as adaptive lie detectors. Journal of Applied Research in Memory \& Cognition, 4, 335-343. http://dx.doi.org/10 $.1016 /$ j.jarmac.2015.06.002

Street, C. N. H., Bischof, W. F., Vadillo, M. A., \& Kingstone, A. (2016). Inferring others' hidden thoughts: Smart guesses in a low diagnostic world. Journal of Behavioral Decision Making, 29, 539549. http://dx.doi.org/10.1002/bdm.1904

Street, C. N. H., \& Vadillo, M. A. (2016). Can the unconscious boost lie detection accuracy? Current Directions in Psychological Science, 25, 246-250. http://dx.doi.org/10.1177/0963721416656348
Tan, J. H., Luan, S., \& Katsikopoulos, K. V. (2017). A signal-detection approach to modeling forgiveness decisions. Evolution and Human Behavior, 38, 27-38. http://dx.doi.org/10.1016/j.evolhumbehav.2016.06.004

ten Brinke, L., Stimson, D., \& Carney, D. R. (2014). Some evidence for unconscious lie detection. Psychological Science, 25, 1098-1105. http://dx.doi .org/10.1177/0956797614524421

ten Brinke, L., Vohs, K. D., \& Carney, D. R. (2016). Can ordinary people detect deception after all? Trends in Cognitive Sciences, 20, 579-588. http:// dx.doi.org/10.1016/j.tics.2016.05.012

van den Assem, M. J., Van Dolder, D., \& Thaler, R. H. (2012). Split or steal? Cooperative behavior when the stakes are large. Management Science, 58, 2-20. http://dx.doi.org/10.1287/mnsc. 1110 .1413

Vrij, A. (2008). Detecting lies and deceit: Pitfalls and opportunities. Hoboken, NJ: Wiley.

Wagenmakers, E. J. (2007). A practical solution to the pervasive problems of $p$ values. Psychonomic Bulletin \& Review, 14, 779-804. http://dx.doi.org/ 10.3758/BF03194105

Watkins, I. J., \& Martire, K. A. (2015). Generalized linear mixed models for deception research: Avoiding problematic data aggregation. Psychology, Crime \& Law, 21, 821-835. http://dx.doi.org/ 10.1080/1068316X.2015.1054384

Received December 20, 2016 Revision received June 2, 2017 Accepted June 6, 2017 